\title{
THE ENGLISH DATIVE ALTERNATION AS AN ADAPTATION TO CHANGES IN THE CONSTRUCTIONAL NETWORK
}

\author{
EVA ZEHENTNER*1 \\ *Corresponding author: eva.zehentner@york.ac.uk \\ ${ }^{1}$ Department of Language and Linguistic Science, University of York, York, UK
}

This paper investigates the history of the English dative alternation, i.e. the fact that most ditransitive, three-participant verbs in Present Day English mainly occur in two different constructions, the double object construction (DOC, 1 ) on the one hand, and a prepositional construction with to (to-POC, 2) on the other hand.

(1) John gave Mary a book.

(2) John gave a book to Mary.

More specifically, the paper discusses the emergence of this alternation as an adaptive response to or evolutionary effect of changes in the constructional environment of the patterns involved. This is argued to work in a two-fold way. On the one side, the alternation as such is claimed to reflect adaptive changes to system-wide changes such as the loss of case marking or the increasing fixation of word order in the history of English. On the other side, the specific features of the members of the dative alternation are seen as the result of two constructions adapting to each other once they become linked in the network. Both these assumptions rest on and were tested on the basis of different methodologies:

First, an evolutionary game theoretic model (e.g. Hofbauer \& Sigmund, 1998) was applied to the issue at hand. This method, originally a branch of applied mathematics, is used to "stud[y] the general problem of strategy selection and its propagation across a population" (Deo, 2015) and has recently also been extended to linguistics (e.g. Jaeger, 2008; Deo, 2015). The results of our game demonstrate that under certain conditions (reflecting universal principles such as end-focus) broader changes can indeed lead to the establishment of a close link between originally unrelated constructions. 
Second, the findings of a large-scale corpus study of the Penn-Helsinki Parsed Corpus of Middle English (PPCME2) were drawn on to investigate the constructions' development in more detail. The data show that Middle English saw the resident DOC and the innovative to-POC entering into a state of stable co-existence, with the nominal construction as the stronger part, and the prepositional construction as the weaker one. This development is then taken to constitute the outcome of competition between two constructional variants, which has not resulted in the ousting of one competitor, but has instead led to the establishment of a cooperative relationship between the patterns (cf. e.g. Berg, 2014). That this association is mutually beneficial is supported by the existence of positive priming effects between the constructions (cf. Perek, 2015), but also by the division of labour-situation evidenced by them: Both patterns have differentiated according to discourse-pragmatic features such as givenness (e.g. Bresnan et al., 2007). Interestingly enough, however, the constructions also exhibit signs of what has recently been dubbed 'attraction' (De Smet et al., subm.), meaning that the variants have formally and functionally aligned to each other. The constructions have thus differentiated in some aspects, but have become more similar in respect to others. In this paper, both niche construction/ differentation and attraction are interpreted as indicators of constructional 'coevolution', i.e. constructions mutually adapting to each other.

\section{References}

Berg, T. (2014). Competition as a unifying concept for the study of language. The Mental Lexicon, 9, 338-370.

Bresnan, J., Cueni, A., Nikitina, T. \& Baayen, R.H. (2007). Predicting the dative alternation. In G. Bouma, I. Kraemer and J. Zwarts (Eds.), Cognitive foundations of interpretation (pp. 64-94). Amsterdam: Royal Netherlands Academy of Science.

Deo, A. (2015). The semantic and pragmatic underpinnings of grammaticalization paths: The progressive and the imperfective. Semantics and Pragmatics, $8(14), 1-52$.

De Smet, H., D'Hoedt, F., Fonteyn, L. \& van Goethem, C. (submitted). The changing functions of competing forms: Attraction and differentiation.

Hofbauer, J. \& Sigmund, K. (1998). Evolutionary games and population dynamics. Cambridge: Cambridge University Press.

Jaeger, G. (2008). Applications of game theory in linguistics. Language and Linguistics Compass, 2(3), 408-421.

Perek, F. (2015). Argument structure in usage-based construction grammar: Experimental and corpus-based perspectives. Amsterdam: Benjamins. 